\title{
PENGARUH APLIKASI PUPUK POLYHALITE DAN KCI TERHADAP KADAR K DAN PERTUMBUHAN BIBIT TANAMAN JERUK PAMELO (Citrus maxima) DI KEBUN PERCOBAAN BALITJESTRO, BATU \\ Effect of Polyhalite and KCl Fertilizer Application on the K Content and Growth of Pamelo Citrus Seedlings (Citrus maxima) in the BALITJESTRO Experimental Garden, Batu
}

\author{
Retno Suntari $^{1 *}$, Sutopo ${ }^{2}$, Aryo Gilang Maudyansa ${ }^{1}$ \\ ${ }^{1}$ Jurusan Tanah, Fakultas Pertanian, Universitas Brawijaya, Malang \\ ${ }^{2}$ Balai Penelitian Tanaman Jeruk dan Buah Subtropika, Batu \\ *Penulis korespondensi: retnosuntari@ub.ac.id
}

\begin{abstract}
There are still many farmers in Indonesia who use a single fertilizer such as N, P, or K fertilizer. While the needs of plant nutrients are not only that nutrients but also other macronutrients. One of single fertilizer used is $\mathrm{KCl}$ fertilizer which only contains essential $\mathrm{K}$ nutrients and micro $\mathrm{Cl}$ nutrient elements. To overcome this problem, another source of $\mathrm{K}$ fertilizer that does not contain $\mathrm{Cl}$ is used, especially in Pamelo citrus nurseries. POLY4 fertilizer is used as a source of $\mathrm{K}$ nutrients, because it has an excess of containing several nutrients such as $\mathrm{K}(14 \%), \mathrm{Ca}(17 \%), \mathrm{Mg}(6 \%)$, and S (19\%). This research was conducted at the BALITJESTRO screen house and the Soil Department Laboratory, Faculty of Agriculture, Brawijaya University. The research design used was a completely randomized design with 5 treatments i.e P0 (100\% MOP), P1 (50\% POLY4 + 50\% MOP), P2 (100\% POLY4), P3 (150\% POLY4), and P4 (200\% POLY4). Parameters of this research were plant height, numbers of leaf, soil $\mathrm{pH}$ and exchangeable $\mathrm{K}$, and $\mathrm{K}$ content in plant. Result of this study indicated that application of $50 \%$ POLY4 + 50\% MOP (642 kg ha-1 POLY4 + $\left.150 \mathrm{~kg} \mathrm{ha}^{-1} \mathrm{MOP}\right)$ significantly affected the height and number of leaves of Pamelo orange seedlings in 12 weeks, respectively $6.39 \%$ and $13.6 \%$ compared to 100\% MOP/control (300 $\left.\mathrm{kg} \mathrm{ha}^{-1} \mathrm{MOP}\right)$. Application of 150\% POLY4 $\left(1,927 \mathrm{~kg} \mathrm{ha}^{-1}\right.$ POLY4) significantly increased plant $\mathrm{K}$ level by $9.40 \%$ compared to control $(300 \mathrm{~kg}$ $\left.\mathrm{ha}^{-1} \mathrm{MOP}\right)$. Application of POLY4 fertilizer had no significant effect on $\mathrm{pH}$ and exchangeable $\mathrm{K}$. The best dose of fertilizer in Pamelo citrus nurseries is the application of POLY4 $642 \mathrm{~kg} \mathrm{ha}^{-1}$ POLY4 $+150 \mathrm{~kg} \mathrm{ha}{ }^{-1} \mathrm{MOP}(50 \%$ POLY4 + 50\% MOP).
\end{abstract}

Keywords : Pamelo citrus, polyhalite, POLY4, MOP, soil chemical properties

\section{Pendahuluan}

Pupuk yang banyak digunakan oleh petani saat ini adalah pupuk tunggal dan pupuk majemuk yang hanya mengandung $\mathrm{N}, \mathrm{P}$, dan $\mathrm{K}$. Sedangkan kebutuhan unsur hara oleh tanaman tidak hanya unsur hara tersebut, melainkan beberapa unsur hara makro lainnya. Apabila kebutuhan unsur hara tanaman tidak terpenuhi dengan baik, maka pertumbuhan tanaman tersebut tidak optimal. Salah satu pupuk tunggal yang banyak digunakan oleh petani saat ini adalah pupuk $\mathrm{KCl}$ yang mengandung unsur hara esensial $\mathrm{K}$ dan unsur hara mikro $\mathrm{Cl}$ yang tidak disukai oleh tanaman. Data BPS (2017) menyatakan bahwa data impor $\mathrm{KCl}$ dari tahun 
2011 hingga 2016 berturut-turut 2,25; 1,5; 2,3; 2,35; dan 2,27 juta ton.

Tanaman jeruk Pamelo (Citrus maxima) adalah tanaman buah asli berasal dari Indonesia dan sudah lama dikembangkan. Sentra penghasil jeruk Pamelo di Indonesia terdapat di beberapa provinsi, yaitu Jawa Timur, Bali, Sumatera Utara, Sulawesi Selatan, Jawa Tengah, dan Jawa Barat. Produksi jeruk Pamelo di Jawa Timur dari tahun 2013-2017 berturut-turut mencapai 20.793, 23.678, 15.160, 19.945, dan 20.543 ton (BPS, 2018). Produksi buah jeruk Pamelo yang fluktuatif bisa terjadi akibat kebutuhan unsur hara tanaman yang tidak terpenuhi dengan baikmaupun kualitas bibit jeruk yang rendah. Hal ini dapat mempengaruhi kualitas dan kuantitas produksi tanaman jeruk. Oleh karena itu dibutuhkannya pemupukan yang efisien pada pembibitan tanaman jeruk agar pertumbuhan jeruk optimal.

Pemupukan dapat dilakukan dengan menggunakan pupuk anorganik atau organik. Salah satu pupuk anorganik yang mengandung unsur hara $\mathrm{K}$ adalah pupuk POLY4 untuk memenuhi kebutuhan tanaman terhadap beberapa unsur hara. Pupuk POLY4 merupakan pupuk yang berbahan dasar polyhalite $\left(\mathrm{K}_{2} \mathrm{Ca}_{2} \mathrm{Mg}\left(\mathrm{SO}_{4}\right)_{4} 2 \mathrm{H}_{2} \mathrm{O}\right)$. Pupuk ini berasal dari bahan tambang mineral alami yang tidak mengandung $\mathrm{Cl}$ dan mengandung beberapa unsur hara esensial seperti $\mathrm{K}, \mathrm{Ca}, \mathrm{Mg}$, dan $\mathrm{S}$ (Yermiyahu et al., 2017). Sehingga pupuk yang dapat digunakan sebagai pengganti pupuk $\mathrm{KCl}$ dan tidak mengandung $\mathrm{Cl}$ adalah pupuk POLY4. Penelitian yang dilakukan oleh Mello et al. (2018) yaitu melihat respon pertumbuhan tomat dengan membandingkan aplikasi Polyhalite, $\mathrm{KCl}$, dan Kalium Sulfat $\left(\mathrm{K}_{2} \mathrm{SO}_{4}\right)$ dengan dosis 125, 250, dan $375 \mathrm{~kg} \mathrm{ha}^{-1} \mathrm{~K}_{2} \mathrm{O}$. Aplikasi polyhalite dapat meningkatkan produksi dan serapan $\mathrm{K}$ pada buah tanaman tomat dan dosis terbaik didapatkan pada $375 \mathrm{~kg}$ $\mathrm{ha}^{-1} \mathrm{~K}_{2} \mathrm{O}$. Hasil penelitian Pavuluri et al. (2017) dengan membandingkan aplikasi POLY4 $(20 \mathrm{~kg}$ $\left.\mathrm{ha}^{-1} \mathrm{~K}_{2} \mathrm{O}\right)$ dengan aplikasi NP $\left(120 \mathrm{~kg} \mathrm{ha}^{-1} \mathrm{~N}\right.$ dan $\left.30 \mathrm{~kg} \mathrm{ha}^{-1} \mathrm{P} 2 \mathrm{O} 5\right), \mathrm{KCl}\left(20 \mathrm{~kg} \mathrm{ha}^{-1} \mathrm{~K}_{2} \mathrm{O}\right)$, dan $\mathrm{KCl}+$ kieserite $\left(28 \mathrm{~kg} \mathrm{ha}^{-1}\right)$. Diketahui bahwa aplikasi POLY4 dapat meningkatkan hasil panen tomat dibandingkan dengan perlakuan Pupuk $\mathrm{N}$ dan $\mathrm{P}, \mathrm{KCl}$, dan $\mathrm{KCl}+$ kieserite.
Penelitian pupuk polyhalite terhadap pertumbuhan dan produksi tanaman jeruk maupun bibit jeruk belum banyak dilakukan di Indonesia, sehingga pada penelitian ini menggunakan pupuk POLY4 yang diaplikasikan pada tanaman jeruk saat fase pembibitan. Penelitian pada bibit tanaman jeruk dilakukan di BALITJESTRO dengan media tanam yang berasal dari endapan sungai Ledogan, Batu yang memiliki kandungan unsur hara $\mathrm{K}$ rendah yaitu 0,03 me $100 \mathrm{~g}^{-1}$ dan $\mathrm{pH}$ sangat masam $(3,6)$. Oleh karena itu, tujuan dari penelitian ini untuk mengetahui pengaruh aplikasi pupuk POLY4 terhadap kadar $\mathrm{K}$ dan pertumbuhan bibit tanaman jeruk bibit jeruk Pamelo varietas Bageng, mengetahui sifat kimia tanah pada media pertumbuhan serta mengetahui dosis terbaik pupuk POLY4 pada fase pembibitan tanaman jeruk Pamelo.

\section{Bahan dan Metode}

\section{Waktu dan lokasi penelitian}

Kegiatan penelitian ini dilaksanakan mulai Bulan Januari hingga Juli 2019. Penelitian dilakukan di screen house Kebun Percobaan Tlekung Balai Penelitian Tanaman Jeruk dan Buah Subtropika dan analisis laboratorium dilaksanakan di Laboratorium Kimia Jurusan Tanah, Fakultas Pertanian, Universitas Brawijaya. Hasil analisis tanah awal disajikan pada Tabel 1. Hasil analisis tanah menunjukkan nilai $\mathrm{pH}$ 3,58 dalam kriteria sangat masam, nilai C-Organik dan $\mathrm{N}$ total berturut-turut $0,89 \%$ dan $0,16 \%$ dengan kriteria sangat rendah dan rendah, KTK (9,97 me $100 \mathrm{~g}$ 1) dan $\mathrm{Ca}\left(2,76 \mathrm{me} 100 \mathrm{~g}^{-1}\right)$ dalam kriteria rendah, $\mathrm{Mg}\left(0,42 \mathrm{me} 100 \mathrm{~g}^{-1}\right)$, dan $\mathrm{Na}\left(0,24 \mathrm{me} 100 \mathrm{~g}^{-1}\right)$ dalam kriteria rendah, sedangkan $\mathrm{K}(0,03$ me $\left.100 \mathrm{~g}^{-1}\right)$ dalam kriteria sangat rendah, dan memiliki kejenuhan basa 34,60\% dengan kriteria rendah. Tekstur tanah adalah pasir dengan fraksi pasir, debu, dan liat berturut-turut $88 \%, 6 \%$, dan $6 \%$. Hasil analisis tersebut sesuai dengan ciri-ciri tanah berpasir berdasarkan penelitian yang dilakukan oleh Darlita et al. (2017) yaitu memiliki $\mathrm{pH}$ yang sangat masam $(3,95)$, kandungan $\mathrm{N}$ total memiliki kriteria yang rendah $(0,1 \%)$, KTK memiliki kriteria yang rendah $\left(9,44\right.$ me $\left.100 \mathrm{~g}^{-1}\right)$, dan kandungan Kalium memiliki kriteria yang rendah $\left(0,02\right.$ me $\left.100 \mathrm{~g}^{-1}\right)$. 
Tabel 1. Analisis tanah awal (BPTP, 2018).

\begin{tabular}{lcc}
\hline Analisis Dasar Tanah & Nilai & Kriteria *) \\
\hline $\mathrm{pH} \mathrm{H}$ O & 3,60 & Sangat Masam \\
$\mathrm{C}-$ Organik $(\%)$ & 0,89 & Sangat Rendah \\
$\mathrm{N}(\%)$ & 0,16 & Rendah \\
$\mathrm{C} / \mathrm{N}$ Rasio & 5.56 & Rendah \\
$\mathrm{KTK}\left(\mathrm{me} 100 \mathrm{~g}^{-1}\right)$ & 9,97 & Rendah \\
Susunan Kation & & \\
$\mathrm{Ca}\left(\mathrm{me} 100 \mathrm{~g}^{-1}\right)$ & 2,76 & Rendah \\
$\mathrm{Mg}\left(\mathrm{me} 100 \mathrm{~g}^{-1}\right)$ & 0,42 & Rendah \\
$\mathrm{K}\left(\mathrm{me} 100 \mathrm{~g}^{-1}\right)$ & 0,03 & Sangat Rendah \\
$\mathrm{Na}\left(\mathrm{me} 100 \mathrm{~g}^{-1}\right)$ & 0,24 & Rendah \\
$\mathrm{Kejenuhan} \mathrm{basa}(\%)$ & 34,60 & Rendah \\
Fraksi & & \\
Pasir $(\%)$ & 88 & \\
Debu $(\%)$ & 6 & Pasir \\
Liat $(\%)$ & 6 & \\
\hline
\end{tabular}

Keterangan: *) Kriteria kadar hara tanah berdasarkan Balai Penelitian Tanah (2009).

\section{Metode penelitian}

Penelitian ini menggunakan Rancangan Acak Lengkap (RAL) dengan 5 perlakuan dan ulangan sebanyak 4 kali. Perlakuan pada penelitian yang dilakukan yaitu P0 (kontrol), P1 $(50 \% \mathrm{KCl}+$ $50 \%$ POLY4), P2 (100\% POLY4), P3 (150\% POLY4), dan P4 (200\% POLY4). Bibit jeruk Pamelo yang digunakan adalah jeruk Pamelo varietas Bageng yang diperbanyak dengan metode okulasi dengan batang bawah JC (Javansche Citroen). Bibit dipilih berdasarkan tinggi tanaman dan jumlah daun yang seragam.

Perawatan yang dilakukan adalah penyiraman, dan penyiangan gulma. Penyiraman dilakukan sebanyak 3 hari sekali dengan air sebanyak $240 \mathrm{ml}$ polybag- $^{-1}$. Penyiangan dilakukan secara manual menggunakan tangan dengan mencabut gulma yang berada disekitar bibit setiap 1 minggu sekali. Aplikasi pupuk POLY4, ZA, TSP, dan KCl dilakukan pada bibit yang telah diokulasi (berumur 2 bulan), pemupukan dilakukan pada bulan pertama, kedua, dan ketiga. Dosis pupuk yang diaplikasikan menurut rekomendasi pemupukan dari Boughalleb et al. (2011) yaitu $180 \mathrm{~kg} \mathrm{ha}^{-1} \mathrm{~N}$, $90 \mathrm{~kg} \mathrm{ha}^{-1} \mathrm{P}_{2} \mathrm{O}_{5}$, dan $180 \mathrm{~kg} \mathrm{ha}^{-1} \mathrm{~K}_{2} \mathrm{O}$ dan aplikasi POLY4 berdasarkan rekomendasi $\mathrm{K}$ menyesuaikan dengan kadar $\mathrm{K}$ dalam POLY4 $(14 \%)$.

\section{Parameter pengamatan}

Parameter pengamatan dalam penelitian ini yaitu pada tanaman terdiri dari kadar $\mathrm{K}$, tinggi tanaman, dan jumlah daun. Parameter pengamatan pada tanah terdiri dari $\mathrm{pH}$ dan $\mathrm{K}_{\mathrm{dd}}$. Pengamatan tinggi dan jumlah daun dilakukan sebanyak 3 kali (4, 8, 12 MSA (Minggu Setelah Aplikasi)) selama penelitian di lapang berlangsung. Pengamatan $\mathrm{pH}$ dan $\mathrm{K}_{\mathrm{dd}}$ tanah dilakukan setelah penelitian di lapang selesai dilaksanakan.

\section{Analisis data}

Data yang diperoleh dianalisis dengan menggunakan analisis ragam (ANOVA) taraf $5 \%$ untuk mengetahui pengaruh dari perlakuan. Apabila terdapat pengaruh, selanjutnya dilakukan uji lanjut dengan menggunakan DMRT taraf 5\% untuk mengetahui perbedaan antar perlakuannya. Analisis ragam dilakukan dengan menggunakan software Genstat 12th Edition.

\section{Hasil dan Pembahasan}

\section{Tinggi tanaman}

Pada pengamatan 4 MSA dan 8 MSA, perlakuan tidak berpengaruh nyata terhadap tinggi bibit tanaman jeruk, tetapi berpengaruh nyata pada pengamatan 12 MSA (Tabel 2). Hasil terbaik didapatkan pada perlakuan P1 dengan rerata tinggi tanaman $51,55 \mathrm{~cm}$ dengan peningkatan sebesar 6,39\% dibandingkan kontrol. Hasil tersebut didukung oleh pernyataan oleh Farhad et al. (2010) bahwa unsur hara K memegang peranan penting dalam metabolisme tanaman antara lain terlibat dalam beberapa proses fisiologi. Ditambahkan bahwa aplikasi K dan S berpengaruh nyata dalam meningkatkan pertumbuhan tanaman, hal ini sesuai dengan kandungan POLY4 yang mengandung $\mathrm{K}$ dan $\mathrm{S}$.

\section{Jumlah daun}

Rerata jumlah daun memiliki pola yang sama dengan rerata tinggi tanaman yaitu tidak terdapat pengaruh nyata dari perlakuan terhadap jumlah daun pada 4 dan 8 MSA tetapi berpengaruh pada pengamatan 12 MSA (Tabel 3). Jumlah daun tertinggi didapatkan pada perlakuan P1 yaitu 25 helai dengan peningkatan 
sebesar 13,60\% dibandingkan dengan perlakuan kontrol. Kalium berperan penting dalam transportasi air dan unsur hara pada jaringan xylem dan floem, sehingga unsur hara kalium sangat penting terhadap pertumbuhan daun tanaman (Thomas dan Thomas, 2009).

Tabel 2. Pengaruh aplikasi pupuk POLY4 terhadap tinggi bibit jeruk Pamelo.

\begin{tabular}{ccccc}
\hline Perlakuan & \multicolumn{2}{c}{ Rerata Tinggi Bibit Jeruk Pamelo (cm) } & \multirow{2}{*}{ Peningkatan (\%) } \\
\cline { 2 - 4 } & 4 MSA & 8 MSA & 12 MSA & \\
\hline P0 & 34,33 & 34,32 & $48,45 \mathrm{bc}$ & - \\
P1 & 32,00 & 34,77 & $51,55 \mathrm{~d}$ & 6,39 \\
P2 & 30,22 & 32,17 & $47,60 \mathrm{~b}$ & -1.75 \\
P3 & 30,32 & 32,85 & $50,88 \mathrm{~cd}$ & 5.01 \\
P4 & 29,92 & 31,75 & $44,10 \mathrm{a}$ & -8.97 \\
\hline
\end{tabular}

Keterangan: Angka pada kolom yang sama yang diikuti huruf sama menunjukkan tidak berbeda nyata pada uji Duncan taraf 5\%; P0 (Kontrol), P1 (50\% POLY4 + 50\% KCl), P2 (100\% POLY4), P3 (150\% POLY4), dan P4 (200\% POLY4).

Tabel 3. Pengaruh aplikasi pupuk POLY4 terhadap jumlah daun bibit jeruk Pamelo.

\begin{tabular}{ccccc}
\hline Perlakuan & \multicolumn{2}{c}{ Rerata Jumlah Daun Bibit Jeruk Pamelo (helai) } & \multirow{2}{*}{ Peningkatan (\%) } \\
\cline { 2 - 4 } & 4 MSA & 8 MSA & 12 MSA & \\
\hline P0 & 15 & 16 & $22 \mathrm{a}$ & - \\
P1 & 16 & 17 & $25 \mathrm{c}$ & 13,60 \\
P2 & 16 & 16 & $23 \mathrm{ab}$ & 4,54 \\
P3 & 16 & 16 & $24 \mathrm{~b}$ & 9,09 \\
P4 & 15 & 16 & $22 \mathrm{a}$ & 0,00 \\
\hline
\end{tabular}

\section{pH tanah}

Aplikasi pupuk POLY4 tidak memberikan pengaruh nyata terhadap $\mathrm{pH}$ tanah pada semua perlakuan dan tidak mengubah kriteria $\mathrm{pH}$ dibandingkan dengan $\mathrm{pH}$ tanah awal. Rerata nilai $\mathrm{pH}$ disajikan pada Tabel 4.

Tabel 4. Pengaruh aplikasi pupuk POLY4 terhadap $\mathrm{pH}$ pada tanah $12 \mathrm{MSA}$.

\begin{tabular}{ccc}
\hline Perlakuan & pH Tanah & Kriteria* \\
\hline P0 & 3,9 & Sangat Masam \\
P1 & 4,0 & Sangat Masam \\
P2 & 3,9 & Sangat Masam \\
P3 & 4,1 & Sangat Masam \\
P4 & 4,1 & Sangat Masam \\
\hline
\end{tabular}

\section{$K_{d d} \operatorname{tanah}$}

Aplikasi pupuk POLY4 tidak berpengaruh nyata terhadap $\mathrm{K}_{\mathrm{dd}}$ tanah media tanam. Rerata nilai $\mathrm{K}$ disajikan pada Tabel 5. Semua perlakuan mampu meningkatkan nilai $\mathrm{K}$ dalam tanah apabila dibandingkan dengan nilai $\mathrm{K}$ pada analisis tanah awal dari 0,03 me $100 \mathrm{~g}^{-1}$ menjadi lebih besar dari 0,30 me $100 \mathrm{~g}^{-1}$. Kriteria $K_{\text {dd }}$ awal sangat rendah menjadi rendah kecuali pada perlakuan P2 (sedang). Penelitian yang telah dilakukan memberikan hasil yang lebih rendah dari pada penelitian yang dilakukan oleh Kumar et al. (2006), bahwa nilai $K_{\text {dd }}$ tertinggi didapatkan pada dosis pupuk $\mathrm{KCl} 150 \mathrm{~kg} \mathrm{ha}^{-1}$ (0,50 me 100 $\left.\mathrm{g}^{-1}\right)$. Penelitian lain yang dilakukan oleh Abdillah et al. (2011) bahwa aplikasi pupuk K memberikan pengaruh yang nyata terhadap peningkatan $\mathrm{K}_{\text {dd. }}$. Perlakuan yang terbaik adalah aplikasi dosis $144 \mathrm{~kg} \mathrm{ha}^{-1} \mathrm{~K}_{2} \mathrm{O}$ dapat menunjukkan nilai $\mathrm{K}$ tertinggi yaitu 0,18 me 100 $\mathrm{g}^{-1}$ dibandingkan dengan perlakuan yang lain (36,72 dan $108 \mathrm{~kg} \mathrm{ha}^{-1} \mathrm{~K}_{2} \mathrm{O}$ ).

Tabel 5. Pengaruh aplikasi pupuk POLY4 terhadap $\mathrm{K}_{\text {dd }}$ pada tanah $12 \mathrm{MSA}$.

\begin{tabular}{ccc}
\hline Perlakuan & $\mathrm{K}_{\mathrm{dd}}(\mathrm{me} 100 \mathrm{~g}-$ & Kriteria* $^{*}$ \\
\hline
\end{tabular}




\begin{tabular}{lll}
\hline P0 & 0,37 & Rendah \\
P1 & 0,38 & Rendah \\
P2 & 0,41 & Sedang \\
P3 & 0,38 & Rendah \\
P4 & 0,36 & Rendah \\
\hline
\end{tabular}

\section{Kadar $K$ tanaman}

Unsur hara $\mathrm{K}$ diserap tanaman dalam bentuk $\mathrm{K}^{+}$, memiliki mobilitas yang tinggi, sehingga dapat ditransformasikan atau disalurkan ke bagian tanaman yang lain yang kekurangan unsur hara tersebut (Nugroho, 2015). Hasil analisis ragam menunujukan aplikasi pupuk POLY4 berpengaruh nyata terhadap kadar $\mathrm{K}$ tanaman. Hasil rerata kadar $\mathrm{K}$ pada bibit tanaman jeruk disajikan pada Tabel 6 .

Tabel 6. Pengaruh aplikasi pupuk POLY4 terhadap kadar K bibit jeruk Pamelo.

\begin{tabular}{ccc}
\hline Perlakuan & $\begin{array}{c}\text { Kadar K } \\
\mathbf{( \% )}\end{array}$ & $\begin{array}{c}\text { Peningkatan } \\
\mathbf{( \% )}\end{array}$ \\
\hline P0 & $2,34 \mathrm{a}$ & - \\
P1 & $2,31 \mathrm{a}$ & $-1,28$ \\
P2 & $2,46 \mathrm{~b}$ & 5,12 \\
P3 & $2,56 \mathrm{c}$ & 9,40 \\
P4 & $2,50 \mathrm{bc}$ & 6,83 \\
\hline
\end{tabular}

Kadar K tertinggi didapatkan pada perlakuan P3 (150\% POLY4) yang memiliki nilai kadar $\mathrm{K}$ sebesar 2,56\% dengan peningkatan 9,40\% dibandingkan dengan perlakuan P0 (kontrol). Kadar K tertinggi tidak pada perlakuan dengan dosis tertinggi hal ini sejalan dengan penelitian Fernandez dan Guzman (2013) bahwa kadar K tertinggi pada tanaman jeruk Pamelo didapatkan pada perlakuan $150 \mathrm{~g}$ tanaman $^{-1} \mathrm{KCl}$ yaitu sebesar $1,06 \%$ dibandingkan dengan perlakuan yang lain (225 g KCl tanaman ${ }^{-1}$ dan kontrol). Penyerapan unsur hara yang optimal oleh tanaman dipengaruhi oleh pengaplikasian pupuk yang tepat, sehingga pemupukan harus sesuai dengan kebutuhan tanaman, serapan hara, dan kondisi unsur hara dalam tanah (Mann et al., 2010).

\section{Kesimpulan}

Aplikasi dosis pupuk 50\% POLY4 $+50 \% \mathrm{KCl}$ $\left(642 \mathrm{~kg} \mathrm{ha}^{-1}\right.$ POLY4 $\left.+150 \mathrm{~kg} \mathrm{ha}^{-1} \mathrm{KCl}\right)$ berpengaruh nyata meningkatkan rerata tinggi dan jumlah daun bibit tanaman jeruk Pamelo pada 12 MSA berturut-turut sebesar 6,39\% dan $13,60 \%$ dibandingkan dengan $100 \%$ $\mathrm{KCl} /$ kontrol $\left(300 \mathrm{~kg} \mathrm{ha}^{-1} \mathrm{KCl}\right)$. Aplikasi 150\% POLY4 (1.927 kg ha-1 POLY4) berbeda nyata meningkatkan kadar $\mathrm{K}$ tanaman sebesar 9,40\% dibandingkan dengan $100 \% \mathrm{KCl} /$ kontrol (300 $\mathrm{kg} \mathrm{ha}{ }^{-1} \mathrm{KCl}$ ). Aplikasi pupuk POLY4 tidak berpengaruh nyata terhadap $\mathrm{pH}$ dan $\mathrm{K}_{\mathrm{dd}}$. Dosis pupuk terbaik pada pembibitan tanaman jeruk Pamelo adalah aplikasi 50\% POLY4 + 50\% KCl (642 kg ha-1 POLY4 + $\left.150 \mathrm{~kg} \mathrm{ha}^{-1} \mathrm{KCl}\right)$.

\section{Daftar Pustaka}

Abdillah, A., Syamsiyah, J., Riyanto, D. dan Minardi, S. 2011. Pengaruh pupuk zeolit dan kalium terhadap ketersediaan dan serapan $\mathrm{K}$ di lahan berpasir Pantai Kulonprogo, Yogyakarta. Bonorowo Wetlands 1 (1): 1-7.

Badan Pusat Statistik. 2017. Impor Pupuk Menurut Negara Asal Utama. www.bps.go.id. Diakses tanggal 28 Desember 2018.

Badan Pusat Statistik. 2018. Produksi Sayuran dan Buah-buahan Tahunan di Jawa Timur Tahun 2008-2017 (ton). www.jatim.bps.go.id. Diakses tanggal 3 Desember 2018.

Boughalleb, F., Mhamdi, M. and Hajlaoui, H. 2011. Response of young citrus trees to NPK fertilization under greenhouse and field conditions. Agricultural Journal 6(3):66-73.

BPTP (Badan Penelitian dan Pengembangan Pertanian). 2018. Laporan Hasil Pengujian Tanah. No 251.1/166/LT/12/2018.

Darlita, RR., Joy, B. dan Sudirja, R. 2017. Analisis beberapa sifat kimia tanah terhadap peningkatan produksi kelapa sawit pada tanah pasir di Perkebunan Kelapa Sawit Selangkun. Jurnal Agrikultura 28(1):15-20.

Farhad, I.S.M., Islam, M.N., Hoque, S. and Bhuiyan, M.S.I. 2010. Role of potassium and sulphur on the growth, yield, and oil content of soybean (Glycine max L.). Journal of Plant Science 3 (2): 99103.

Fernandez, A. and Guzman C.D. 2013. Quality and nutrition of Pummelo as influenced by potassium. Journal of Environmental Science and Engineering 1(2):97-105.

Kumar, N., Meenakshi, N., Suresh, J. and Nosov, V. 2006. Effect of potassium nutrition on growth, 
Jurnal Tanah dan Sumberdaya Lahan Vol 7 No 1 : 87-92, 2020

e-ISSN:2549-9793, doi: 10.21776/ub.jts1.2020.007.1.11

yield and quality of papaya (Carica papaya L.). Indian Journal of Fertilizers, 2(4), 43-47.

Mann K.K., Waldo, L.J., Hostler, K., Mann, R.S. and Schumann, A.W. 2010. Estimating relative nutrient uptake by mature citrus trees in field conditions. Proceedings of the Florida State Horticultural Society 3(12):67-73.

Mello, S.D.C., Tonhati, R., Neto, D.D., Darapuneni, M. and Pavuluri, K. 2018. Response of tomato to polyhalite as a multinutrient fertilizer in Southeast Brazil. Journal of Plant Nutrition 41(16) 2126-2140.

Nugroho, P.A. 2015. Dinamika hara kalium dan pengelolaannya di perkebunan karet. Warta Perkaretan 34(2):89-102.
Pavuluri, K., Malley, Z., Mzimbiri, M. K., Lewis, T.D. and Meakin, R. 2017. Evaluation of polyhalite in comparison to muriate of potash for corn grain yield in the Southern Highlands of Tanzania. African Journal of Agronomy 5(3):325-332.

Thomas, T.C. and Thomas A.C. 2009. Vital role of potassium in the osmotic mechanism of stomata aperture modulation and its link with potassium deficiency. Plant Signal Behaviour 4(3) 240-243.

Yemiryahu, U., Zipori, I., Faingold, I., Yusopov, L., Faust, N. and Bar-Tal, A. 2017. Polyhalite as a multi nutrient fertilizer - potassium, magnesium, calcium and sulfate. Israel Journal of Plant Sciences (3)4:145-156. 